\title{
Corrigendum
}

\section{THE CAUSAL RELATIONSHIP BETWEEN CONSANGUINEOUS MARRIAGES AND INFANT MORTALITY IN TURKEY}

\author{
ISMET KOÇ AND MEHMET ALI ERYURT
}

DOI: 10.1017/S002193201600033X, Published by Cambridge University Press, 07 July 2016

This paper uses the terms 'first degree consanguineous', 'first degree relatives' and 'first degree' erroneously; these should read 'first cousin marriages' throughout the paper. It also uses 'second degree' erroneously, and this should read 'second cousin marriages' throughout the paper.

In Tables 5 and 6 the terms 'Not relatives', 'First degree relatives' and 'Other relatives' should read 'Not related', 'First cousin marriages' and 'Other consanguineous marriages', respectively.

These corrections are being made because the terms used in the manuscript should have been in line with common usage.

\section{Reference}

Koç, I. \& Eryurt, M. A. (2016) The causal relationship between consanguineous marriages and infant mortality in Turkey. Journal of Biosocial Science. doi: 10.1017/S002193201600033X 